Artículos

\title{
Experiencias militantes platenses en el final de la Dictadura
} cívico militar, 1980-1983

\author{
Militant experiences from La Plata at the end of the civic \\ military dictatorship, 1980-1983
}

Santilli, Sandra; Quinteros, Guillermo O.

\author{
Sandra Santilli \\ sansantilli@gmail.com \\ Universidad Nacional de La Plata, Argentina \\ Guillermo O. Quinteros \\ goscarquinteros@gmail.com \\ Centro de Historia Argentina y Americana. \\ Universidad Nacional de La Plata, Argentina
}

Cuadernos de $\mathrm{H}$ ideas

Universidad Nacional de La Plata, Argentina

ISSN: $2313-9048$

Periodicidad: Frecuencia continua

vol. 15, núm. 15, e044, 2021

cuadernosdehideas@perio.unlp.edu.ar

Recepción: 21 Febrero 2021

Aprobación: 10 Mayo 2021

URL: http://portal.amelica.org/ameli/jatsRepo/31/312012005/ index.html

DOI: https://doi.org/10.24215/23139048e044

\section{(i) (2)}

Esta obra está bajo una Licencia Creative Commons AtribuciónNoComercial-CompartirIgual 4.0 Internacional.
Resumen: Este artículo se propone dar cuenta de algunas prácticas de la militancia política de un grupo particular platense. Se trata de un puñado de Universitarios que impulsó la creación de la Fundación Eugenio Blanco de la ciudad de La Plata, Argentina. La trayectoria personal de varios de sus protagonistas es conocida en tanto -como se verá- formaron parte del gobierno nacional y de la Universidad. No obstante, se trata de explicar las razones que los animaban a la construcción de aquel colectivo político. Se considera de importancia comprender cuáles eran los aspectos personales y colectivos que los llevaron a reunirse. Sobre todo, interesa ahondar en las trayectorias anteriores a la vuelta a la democracia en tanto que puede contribuir a arrojar un poco más de luz a las explicaciones sobre el triunfo de Raúl Alfonsín en las elecciones de octubre de 1983 y el desarrollo de determinadas políticas de estado. Para la realización de este avance se ha trabajado con bibliografía específica, con una serie de entrevistas con los miembros de la extinta Fundación E. Blanco y con fuentes indirectas procedentes de los periódicos.

Palabras clave: Militancia, La Plata, Dictadura militar, Democracia, Universidad.

Abstract: This article aims to account for some practices of the political militancy of a particular group from La Plata. It is about a handful of University students who promoted the creation of the Eugenio Blanco Foundation in the city of La Plata, Argentina. The personal trajectory of several of its protagonists is known as -as it will be seen- they were part of the national government and the University. However, it is about explaining the reasons that encouraged them to build that political group. It is considered important to understand what were the personal and collective aspects that led them to meet. Above all, it is interesting to delve into the trajectories prior to the return to democracy insofar as it can contribute to shed a little more light on the explanations of the triumph of Raúl Alfonsin in the October 1983 elections and the development of certain policies of condition. To carry out this advance, we have worked with specific bibliography, with a series of interviews with members of the defunct E. Blanco Foundation and with indirect sources from newspapers. 
Keywords: Militancy, La Plata, Military dictatorship, Democracy, University.

\section{INTRODUCCIÓN}

La imagen de expectación frente al posible retorno de la democracia y el llamado a elecciones, era una postal de la coyuntura. La situación de cierre del escenario político había dado, en los últimos tiempos, un giro importante. Este giro radical sucedió después de la derrota de las Fuerzas Armadas argentinas en la guerra de Malvinas (2 de abril-14 de junio de 1982), que operó como el golpe de gracia a los fines de permanencia indefinida en el poder de los militares (Morán, 2018; Lorenz, 2017). Desde entonces y por el resto del año, las páginas del diario local de la ciudad de La Plata publicaron noticias sobre un panorama político todavía transitorio. Por esos meses, los partidos se reincorporaban a la escena pública y distintos sectores comenzaban a movilizar recursos en pos de un futuro democrático que no estaba exento de tensiones (un ejemplo en Franco, 2018a). Intelectuales, políticos y viejos profesores universitarios dejaron a la vista la política represiva, el espíritu mercenario de quienes colaboraron con el régimen, o tergiversaron prácticas para el funcionamiento institucional, así como también revelaron el amiguismo con el que miembros del régimen habían dado rienda suelta en el acceso a los niveles académicos y de conducción universitaria, como era el caso -así se denunciaba- de la Universidad Nacional de La Plata. ${ }^{1}$

En ese marco, se creó la Fundación Eugenio Blanco de la ciudad de La Plata que fue un lugar de reunión para nuclear a intelectuales provenientes de distintas ramas disciplinares -todos ellos profesionales- que de una u otra forma habían compartido experiencia con la militancia reformista, o ellos mismos se identificaban como tales. En este avance de investigación se propone enfocar la atención en el trayecto de algunos de sus miembros, en el modo de hacer política de ese grupo de intelectuales y, particularmente, seguir la evolución de sus ideas en la elaboración de la propuesta educativa universitaria, materializada tiempo después durante el gobierno democrático de Raúl Alfonsín. Los vínculos entre ellos y con otros líderes políticos, profesionales o estudiantiles, sus experiencias de vida militante en las agrupaciones estudiantiles y los lazos generados en el marco de su trabajo docente o en el quehacer partidario, son elementos de análisis que contribuyen a explicar su rápida inserción en el campo político general y universitario en particular.

Para este trabajo se retoma la noción de "intelectual” que describiera Eduardo Devés Valdés (2007) en la comprensión de un grupo contenido de docentes e investigadores del nivel superior así como de políticos, diplomáticos, líderes sociales, entre otros, que tienen la particularidad de elaborar un trabajo que comparten como interlocutores y "son reconocidos como pares al interior del campo" (p. 30) (cfr Altamirano (2006); Monsiváis (2007); Neiburg y Plotkin (2004). En tal sentido, la categoría se apoya en la teoría de los campos de Pierre Bourdieu que posibilita observar cómo los intelectuales toman posición, oposición o de qué modo se mueven en esa relación de fuerzas que se establece en el interior del campo, que pone en juego el capital cultural y deja de manifiesto los comportamientos y criterios que utilizan para legitimar sus prácticas e ideas. Para lograrlo se tornan de importancia -entre otras cuestiones- las publicaciones que producen en común, los mecanismos que esgrimen para hacer su trabajo, las problemáticas que priorizan y/o atienden.

De este modo se identifican algunas conexiones para la toma de decisiones, las prácticas militantes y académicas compartidas, el espacio de reunión, los tipos de vínculos y modos de comunicación, etc., que dan cuenta de las primeras tramas en la constitución de una "red intelectual" mucho más amplia y compleja que la que aquí se esboza. Según la acepción de Devés Valdés hablamos de una red cuando nos referimos a un "conjunto de personas ocupadas en la producción y difusión del conocimiento que se comunican en razón de su actividad profesional a lo largo de los años" (2007, p. 30). Tal como expresó Gonzalo Rubio García, "La importancia de considerar los estudios sobre las redes radica en la posibilidad de poder medir los mecanismos 
de funcionamiento mediante los que operaban y el complejo sistema de vinculos y la circulación de bienes y servicios, materiales e inmateriales' que establecían sus miembros mediante distintos espacios culturales y simbólicos" (el destacado en el original) (2018, p. 4).

Interesa señalar que los intelectuales que se nombran en este artículo tuvieron diferente formación profesional y sus experticias no les impidió ejercer una práctica de militancia en centros de estudiantes, fundaciones, o partidos políticos -en varias ocasiones reunidos en sus locales partidarios- así como trabajar sobre problemáticas sociales en áreas de conocimiento que no eran de su incumbencia académica. Eran economistas, arquitectos, ingenieros, abogados, que se conocieron -varios de ellos- en la auto denominada Liga de Agrupaciones Amigas en los años 60, ${ }^{2}$ y veinte años después, volvieron a vincularse dentro de la Fundación Eugenio Blanco de La Plata. La citada Liga había sido creada por agrupaciones reformistas insertas en distintas unidades académicas que luchaban en el espacio universitario contra las diversas expresiones del comunismo local y en menor medida de las persistentes corrientes clericales. ${ }^{3}$ Era un espacio -según el arquitecto Jorge Lombardi- generado en los encuentros convocados en la casa de Sergio Karakachof.4 Allí, compartían las experiencias mantenidas en sus respectivas Unidades Académicas y las cuestiones de trascendencia como por ejemplo, la elección del aspirante a Presidente de la universidad. ${ }^{5}$ Uno de los objetivos primordiales que perseguían “...era retener los centros, ganar las Federaciones y por fin la FUA. El PC y la FEDE era mayoría (Allí estaban Bernardo Kleinert, Julio Godio -del PC-y Rocha -del PCR)” (Quinteros, Pessacq, Banzato, 2018a, p. 167).

\section{ASPECTOS CONTEXTUALES}

El estudio se circunscribe a comienzos de los años 80 en la ciudad de La Plata, la capital de la provincia de Buenos Aires, donde funcionaban ( $\mathrm{y}$ funcionan) las oficinas de ministerios, juzgados y registros provinciales que eran caja de resonancia de la información que procedía de la Capital Federal. Además, la ciudad albergaba un número importante de la juventud que habían venido de alguno de los municipios tanto de la provincia de Buenos Aires como de otras, a realizar sus estudios universitarios y luego, si las oportunidades laborales se lo permitían, a desarrollarse de manera profesional. Sin embargo, cabe aclarar, que en los tiempos en los que la fundación desempeñó sus actividades, la vida pública estaba aún sujeta a un espacio condicionado por el accionar militar.

Las fisuras que emergieron paulatinamente del seno mismo del régimen dieron lugar a la aparición de noticias que el diario El Día de la ciudad de La Plata publicó sobre la falta de legitimidad política. A su vez, la búsqueda por instalar la apertura democrática estaba asociada a algunos acontecimientos visibles para la sociedad argentina y el mundo, tal como lo había sido la visita de la Comisión Interamericana de Derechos Humanas en 1979 (Franco, 2018b).

Por entonces, el régimen produjo alguna distención sobre el fuerte control social y político que se había venido ejerciendo hasta entonces. El diario El Día informó en ocasión de las fiestas patrias del 9 de julio de 1980 que las Fuerzas Armadas seguirían sus reuniones con representantes partidarios, aunque aún el diálogo político no se había abierto para las principales fuerzas (El Día, 7 de julio de 1980). La apertura a los partidos políticos no fue espontánea ni se dio como producto de la casualidad. Para 1981 había evidencia de que el consenso que había gozado la Junta militar argentina para desempeñarse en el terreno político se disipaba, como consecuencia de los problemas que les había traído la aplicación del programa económico del ministro de economía José Alfredo Martínez de Hoz. El descontento social finalmente se puso de manifiesto, con el llamado a una huelga general y movilización por parte de la Confederación General del Trabajo encabezada por Saúl Ubaldini (Geoghegan, 2021; Sangrilli, 2012). Más tarde, la derrota en la Guerra de Malvinas señalará el final del proyecto militar. En ese sentido, Gabriela Águila (2008) ha señalado que 
Si en el primer quinquenio (1976/1981) el gobierno militar había tenido un importante margen de maniobra para poner en marcha su proyecto económico, social y político, este comenzó a erosionarse de la mano del proceso de deterioro económico y, sobre todo, a partir del catastrófico final de la guerra con Gran Bretaña. Hacia 1982/83 la dictadura ingresó en un periodo conflictivo signado por una crisis en múltiples niveles y una ascendente movilización social y política, incrementando y ampliando las posibilidades de actuación de los grupos opositores (p. 297).

Desde 1978 habían emergido de forma continua reclamos en torno a los “excesos" del sistema represivo, al problema de la desaparición de personas y a los crímenes de lesa humanidad, asuntos que impactaron fuertemente en los organismos internacionales y fueron el germen para la conformación de organismos de derechos humanos locales. ${ }^{6}$ Para enfrentar las acusaciones por sus crímenes y desapariciones, la junta militar generó algunos cambios en su estrategia tanto comunicacional como en la adopción de determinadas políticas. Un ejemplo de ello fue que lanzaron el slogan "Los argentinos somos derechos y humanos", mientras recibían un contingente de refugiados del sudeste asiático atendiendo al llamado a la solidaridad mundial, encabezada por el ACNUR (Bounchanavong, 2016; Azconegui, 2018) ${ }^{7}$

Asimismo, el General Jorge Rafael Videla y luego, su sucesor el también General Roberto Eduardo Viola -ambos presidentes de facto- optaron por algunas iniciativas de apertura al diálogo político con sectores partidarios, gremiales y corporaciones empresariales así como también, ensayaron la incorporación de funcionarios civiles en el estado. La iniciativa de la dictadura logró que algún sector político como el proveniente del Partido Demócrata Progresista se acercara al régimen (Canelo, 2016; Ponisio, 2016). Sin embargo, obligó a todo el arco opositor a tomar posición frente a lo que suponía una salida política. De ahí es que emergiera la Multipartidaria Nacional en julio de 1981, integrada por miembros de la Unión Cívica Radical, el Partido Justicialista, el Partido Intransigente, el Partido Demócrata Cristiano, el Movimiento de Integración y Desarrollo, bajo la expectativa de dar por finalizado el periodo dictatorial y encontrar una salida democrática (Velázquez Ramírez, 2015; Borrelli, \& Raíces, 2019). ${ }^{8}$ Distintas publicaciones de la época dieron cuenta de la convergencia como parte de una estrategia de resistencia pública, con declaraciones de fuerte tinte crítico hacia ese estado de cosas al que había llevado la dictadura. ${ }^{9}$

En esos años 80, enarbolar las banderas de la democracia desafiaba cualquier intento de legitimación por parte de la dictadura militar y neutralizaba cualquiera de las voces que pudieran defender alguna de sus políticas. La elaboración política de la idea de la democracia futura se fue construyendo como el opuesto al autoritarismo. ${ }^{10} \mathrm{Al}$ respecto, Cecilia Lesgart ha planteado que:

\footnotetext{
...se clasificaban modelos institucionales, se adjetivaban actores y comportamientos, dentro y/o fuera del régimen político llamado democrático. (...) Esas clasificaciones binarias se realizaban a través del particular prismático que otorgaba la fórmula Autoritarismo/Democracia, que reducía la complejidad del mundo político en el dualismo autoritarios y/o demócratas. También los proyectos socialistas y la idea de revolución, que hasta allí habían dado sentido a las representaciones del futuro y a la acción política, fueron calificadas con la palabra autoritarismo (Lesgart, 2003, pp. 188-189).
}

El planteo deja ver el campo de posibilidades que generó la transición e incluso en los primeros años de democracia. En ese entonces, era habitual hacer uso de los pares conceptuales Dictadura/Democracia, Autoritarismo/Democracia y otros en la misma óptica para dar cuenta que la política se asumía por oposición a la idea de violencia y que esa tesis determinaba los posicionamientos entre un pasado violento y un presente democrático pacífico. Es decir, en democracia se "intentaban construir tanto instituciones como una cultura política diferentes a esa descripción negativa del pasado realizada mediante el término autoritarismo, y que suponía la convivencia entre diferentes, el diálogo en el espacio público, la construcción del consenso" (Lesgart, 2003, p. 189).

La vuelta a la democracia exigía diferenciarse de los modos autoritarios y afianzar un tipo institucional que revalorizara acciones democráticas. Según Buchbinder, "La construcción universitaria iniciada en el 1983 se llevó a cabo sobre fundamentos que implicaban una visión absolutamente crítica de lo actuado durante la dictadura, pero también de la experiencia de los años setenta" (2005, p. 216). A la afirmación del autor puede 
agregarse el hecho de que quienes suscribían a la idea de que había solo dos opciones, a saber: Democracia o Dictadura, hacían una lectura de la historia más larga, que había comenzado con el golpe de Estado del 6 de septiembre de 1930 efectuado contra el presidente Hipólito Yrigoyen, y terminado en la dictadura más feroz que conociera la Argentina. Las sucesivas alternancias entre dictaduras y gobiernos democráticos, había conducido cada vez, a un incremento de la violencia política y a un descreimiento cada vez mayor en la república democrática. Se trató entonces de rechazar cualquier forma de resolución de los conflictos a través de comportamientos violentos. ${ }^{11}$ Por el contrario, se trataba de imponer la idea de que había que buscar el consenso, de admitir las opiniones disidentes, de incorporar a las minorías al sistema, de fomentar la convivencia ideológica, de establecer un estado de derecho. Lo cual no significó llegar fácilmente al objetivo, ni que se halla puesto en práctica plenamente.

En esas circunstancias -si se prefiere, en ese clima de época- por iniciativa de Pablo Luchessi y Gustavo Callejas nació en 1981 la Fundación Eugenio Blanco en la ciudad de La Plata. Eran jóvenes militantes radicales; el último de los mencionados encargado de solicitar a la Institución ya existente en la Capital Federal, la aprobación de una filial en la ciudad de La Plata. ${ }^{12}$ La conexión con la Fundación se daba porque Callejas había sido funcionario de la Secretaría de Energía de la Nación durante la Presidencia de Arturo Illia y, por ende había entablado relación con el Secretario de Energía y Combustibles Conrado Storani y conocido a otros miembros de aquel gabinete. ${ }^{13}$ Según lo conversado en las entrevistas, Blanco había dejado un buen recuerdo dentro del radicalismo como miembro del gabinete del presidente Illia, pero también, era una Fundación de renombre, conocida en el ámbito y dicha cuestión facilitaba -en teoría - el reconocimiento en el plano local. De ese modo, la sede recién creada de la calle 44 casi esquina 3, albergó a un grupo de militantes radicales cuyo propósito era trabajar en materia de vivienda, energía y educación, con ideas que ya se habían esbozado en los $70 .{ }^{14}$

Este grupo estuvo conformado por al menos dos generaciones de militantes. Fueron quienes estudiaron y se recibieron en la Universidad Nacional de La Plata durante la década de 1960 y, la posterior, es decir quienes se recibieron hacia fines de la década del 70 y principios de los 80 . Como se verá, a partir de 1983, esa militancia ocupó cargos de gestión pública durante el gobierno del Dr Raúl Alfonsín y puso en acción un programa político universitario destinado a las Universidades Argentinas; específicamente para la UNLP. Además tuvo vínculos fuertes con el equipo de gestión gubernamental y compartió con éste la tradición democrática, aquella que valoraba a grandes rasgos la dimensión republicana y el pluralismo y se distanciaba de otras experiencias democráticas del siglo XX que habían hecho hincapié -tal como lo ha dicho Romero“...en el tipo plebliscitario, unanimista y faccioso” (1994, p. 23). Según Luciana Garatte, bajo el gobierno de Alfonsín, se dieron conexiones visibles entre la conducción universitaria, la UCR, y la agrupación estudiantil Franja Morada, y con ello se le dio centralidad a las universidades en "la producción de un consenso en torno del programa de gobierno del presidente Alfonsín y del crecimiento político de su partido, la Unión Cívica Radical” (Garatte, 2008, p. 33; cfr. Beltrán, 2013, pp. 189-232).

En el caso de la UNLP, el rector Ing. Raúl "Otto" Pessacq fue designado en 1983 por el ministro de educación y justicia Dr Carlos Alconada Aramburú, con quien había tomado contacto tiempo atrás por las prácticas políticas de la Fundación Blanco y en los espacios de la militancia radical. ${ }^{15}$ Ambos tuvieron un estrecho vínculo profesional. En esos intercambios habían trabajado la perspectiva que luego se hizo explícita en el decreto 154/83 transitorio dado que planteaba un período de normalización de las Universidades Nacionales. Pessacq recuerda a Alconada como la persona que lo respaldó políticamente, pero también como una figura con quien tuvo la afinidad de criterios necesaria para plantear los objetivos políticos de la universidad pública (Quinteros, 2017). 


\section{¿Por qué Fundación Eugenio Blanco?}

Eugenio Blanco se había desempeñado como contador público en empresas importantes de la capital federal en distintos momentos de su trayectoria. Fue director en empresas tales como los Establecimientos Metalúrgicos Argentinos; la Agrícola Ganadera de San Luis; y el Banco Río de La Plata. A su vez, trabajó en la dirección del Banco Hipotecario Nacional y fue presidente del Banco Central de la República Argentina antes de asumir como ministro de economía. Era un intelectual allegado a Ricardo Balbín -máximo dirigente platense y uno de los líderes más importantes durante décadas de la UCR en el plano nacional- a tal punto que la autodenominada Revolución Libertadora lo incorporó a la cartera de Hacienda con el objetivo de anular las presiones al régimen que ejercía el radicalismo en 1956 (Acuña, 1984). ${ }^{16}$ En ese momento, Blanco implementó el Plan Prebisch pero “...habría ejercido sus funciones con algunas limitaciones en sus atribuciones ya que gran parte de las medidas de conducción política y económica emanaban del Poder Ejecutivo y del Consejo Nacional de Desarrollo (CONADE)...” (Acuña, 1984, p. 151). El economista perteneció -según Acuña- a la "línea blanda" del liberalismo y fue uno de los políticos que apuntó a resolver la cuestión de los salarios a partir de los topes que pusieran las instituciones y no lo mercados (Acuña, 1984b).

Cabe recordar que bajo su gestión de 1956, la Argentina firmó los acuerdos de Bretton Woods e ingreso al Fondo Monetario Internacional y al Banco Mundial. Pero durante la presidencia de Illia Blanco se negó a seguir las políticas que aconsejaba el FMI (devaluación y ajuste fiscal), optando por una inflación moderada hasta lograr estabilizar la situación, cuestión que se logrará en beneficio de un mejor acuerdo con el organismo acreedor (Veronelli y Veronelli Correch, 2004).

Compartió su trabajo con un grupo de asesores, y se encargó de formarlos como expertos en su materia. Por otra parte, ese grupo de asesores compuso un equipo de especialistas que lejos de constituirse en "soldados" de Balbín, se mantuvo al margen de las disputas ideológicas para colaborar con el radicalismo en lo que se podía considerar era su área de conocimiento. Así fue que Germán López, Roque Carranza, Bernardo Grinspun, Alfredo Concepción, Roberto Pena y Féliz Elizalde ocuparon puestos de relevancia en el régimen de los libertadores y más tarde, en el gobierno de Alfonsín. El grupo había nacido alrededor de la figura de Eugenio Blanco en la Facultad de Ciencias Económicas de la Universidad de Buenos Aires y durante un tiempo expresó sus ideas en la revista Definición. En sus escritos “...denunciaron sistemáticamente la oligarquía, el atraso, la miseria y la corrupción social” (Acuña, 1984, p. 143).

$\mathrm{Al}$ momento en que Arturo Illia asumió la primera magistratura de gobierno uno de los grupos de asesores más influyentes dentro del radicalismo era el equipo de Germán López, con quien colaboraban asimismo Antonio Tróccoli y Raúl Afonsín. Durante ese gobierno, Blanco asumió el cargo de Ministro de economía hasta que murió de un modo sorpresivo en agosto de 1964 y fue reemplazado por el político radical Juan Carlos Pugliese. A su vez, algunos investigadores han señalado que tanto Alconada como Blanco fueron de los ministros más influyentes de Arturo Illia, de la línea Intransigente, que debatieron y se opusieron fuertemente a políticas trascendentales como eran la de los contratos petroleros firmada por Arturo Frondizi y que le valieron su posición en el poder. ${ }^{17}$

Con todo, la referencia a Eugenio Blanco en el nombre de la fundación parecía ser más la reivindicación de un grupo de hombres que influyeron de forma directa durante el gobierno de Arturo Illia y que tenían el rasgo particular de ser profesionales con un criterio propio. Es así que la Fundación se constituyó en el año 1968, aunque por el momento no contamos con información suficiente para referirnos a sus actividades. ${ }^{18}$ En cambio se puede corroborar que para 1986 el Directorio de la Fundación, estaba formado 19 miembros de los cuales 8 habían participado en el gabinete presidencial de Illia: el Presidente de la Fundación era el Dr. Luis Augusto Caeiro (ex Secretario Legal y Técnico de la Presidencia); su Vicepresidente $1^{\circ}$ era el Dr. Carlos Alconada Aranburó (ex Ministro de Justicia y Educación); el Vicepresidente $2^{\circ}$ era el Ing. Roque Carranza (ex Secretario Técnico de la CONADE); el Prosecretario era el Dr. Germán López (ex Subsecretario de Trabajo de la Nación; siendo vocales los Doctores Alfredo Concepción, Enrique García Vázquez, Bernardo Grinspun 
y Juan Carlos Pugliese, todos ex miembros de la cartera económica y del Banco Central (Fundación Eugenio A. Blanco, 1986, p.9). ${ }^{19}$

\section{¿Cómo se agruparon?}

La Fundación Eugenio Blanco de La Plata se creó en 1981 bajo el objetivo de conformar grupos técnicos capacitados en asuntos políticos, y se estima que fue inspirada, un año antes, en el Congreso Nacional de Educación del Partido Radical donde se presentaron propuestas de acción gubernamental nacional. El organigrama de la Fundación planteó la conformación de un Comité honorario que fue integrado por figuras conocidas y respetadas en el marco de la militancia y en el medio platense, tal como lo fueron Juan Sábato, Carlos Alconada Aramburú y Andrés Ringuelet. ${ }^{20}$ Según lo manifestado por Raúl Pessacq “eran tipos con 30 años más que nosotros y que tenían una trayectoria que cuando vos mencionabas que el presidente era Alconada Aramburú y los presidentes honorarios eran Ringuelet y Juan Sábato (...) la gente decía esto no es joda”. Además, la fundación disponía de un tesorero, un protesorero y un conjunto de vocales, que reunía a Raúl “Otto” Pessacq, Pablo Luchessi, Jorge Lombardi, Ángel Plastino, Gustavo Callejas, el "negro” Iglesias, David Lagmanovich, entre otros. Ese grupo experimentó un fluido intercambio de ideas que fueron puliendo a lo largo de los encuentros plenarios, las conversaciones telefónicas y las conferencias de prensa. Una de las tareas militantes fue la de salir puerta a puerta, a convencer al público de participar de sus reuniones para compartir sus análisis y propuestas.

Esa Fundación contaba con antecedentes que provenían de los tiempos del régimen de Lanusse, cuando empezaba a abrirse el juego para la salida electoral con el denominado Gran Acuerdo Nacional y algunos de ellos habían trabajado en el Grupo Línea para formar equipos técnicos-profesionales y propuestas de gestión gubernamental. Sin embargo, ese agrupamiento fomentado por el "Chino" -Juan Carlos- Delorenzo había resultado un emprendimiento frustrado al ganar las elecciones Héctor Cámpora como Presidente de la Nación en 1973. Tal como lo describe Pessacq, posteriormente en 1974 y "ante el fracaso de todo, cuando entran los montoneros que nos cagan a piedrazos, empiezan con tiros y amenazas, aparece UDIR" (Pessacq, comunicación personal, 2018). Es decir que después de desbaratarse el Grupo Línea, intentaron impulsar pero ya dentro de la Universidad Nacional de La Plata- la Unión de Docentes e Investigadores Reformistas (UDIR) que se planteó como un grupo abocado a las cuestiones de la universidad y se declaró reformista para incluir a aquellos sectores que no formaban parte del sector procedente de la UCR. ${ }^{21}$

El Grupo Linea había tenido objetivos similares al de la Fundación Eugenio Blanco de La Plata y las propuestas que se presentaron podían leerse como una continuidad de las elaboradas en aquella época. La diferencia consistía en la filiación partidaria. Pessacq ha explicado al respecto que:

...la Fundación Blanco ya era política partidaria, era del Partido Radical, en cambio Línea no era partidaria todavía. Era política no partidaria porque veníamos de la vieja tradición del reformismo, de cuando para ser reformista no tenías que pertenecer a un partido político. Si pertenecías no podías hablar adentro de la universidad, ni tenías contactos. Hasta los 70 , hasta la Franja (Pessacq, 2018, comunicación personal).

En esa explicación Pessacq distinguía los criterios políticos que impusieron los miembros de su grupo de militancia como parte del movimiento reformista universitario y en la relación adoptada con el partido radical. Los reformistas de la Universidad de La Plata habían hecho política sin llevar las cuestiones partidarias al interior del ámbito académico institucional. Esa era una condición sine qua non para cualquier militante reformista que hiciera política dentro del ámbito universitario, hasta por los menos la década del 60. A su vez, esa misma postura también la practicaba la militancia radical dentro del partido al no permitir, por ejemplo, hacer uso de la doble filiación de un militante -reformista y radical- para sumar votos. ${ }^{22}$ Por su parte, Raúl Pistorio lo explicaba con estas palabras: 
Ingresé en la Universidad en la década del 50, con el retorno del Sistema Reformista durante fugaces años, donde concebíamos a Deodoro Roca y Julio González como hermanos mayores y del primero se decía que había sido el autor de la mayor pieza oratoria del movimiento de 1918.

También eran nuestros maestros los hombres del 45 como Calcagno y Martínez Civelli por nombrar a quienes estuvieron al frente de la Universidad que junto con profesores, graduados y los estudiantes, habían triunfado sobre las bayonetas a punta de corazón y coraje. La Reforma Universitaria no sólo era ese ideario y esos hombres de los que conocimos los epígonos en aquellos maestros como Palacios, Mercader, Fassi, etc. a los que vimos transitar por las aulas universitarias, o a los que no pudimos conocer personalmente como a Don Alejandro Korn o Ricardo Rojas, quienes nos dieron un ejemplo de sabiduría y también de moral militante, donde no estaba ajena la política (El Día, 14/06/1983, p. 4). ${ }^{23}$

Ahora bien, casi todos los miembros de Linea terminaron integrándose a la Fundación a excepción de, por ejemplo, algunos militantes que se identificaban con los sectores balbinistas como fue el caso de Luis Julián Lima. ${ }^{24}$ La Fundación estaba marcada por una clara coordinación alfonsinista y según Pessacq, "ni Lima, ni Pistorio (...) tenían nada que ver ni con Alfonsín, ni con la Coordinadora” (Pessacq, comunicación personal, 2018). La Junta Coordinadora Nacional era una corriente del Partido Radical formada en la Juventud Radical que tuvo como miembros a Federico Storani, Marcelo Stubrin, Leopoldo Moreau, Ricardo Laferriere y Jesús Rodríguez, entre otros. ${ }^{25}$ No obstante esto, no era necesario estar afiliado al partido y pertenecer a la coordinadora para formar parte de la fundación. De hecho, Raúl Pessacq estaba afiliado al partido pero no pertenecía al grupo de la coordinadora y, Pablo Luchessi junto a Marcelo Marcó -que en aquel momento eran "una dupla inseparable" - lo convocaron para inaugurar ese espacio de encuentro. Luchessi había conocido a Pessacq en la Facultad cuando cursaba la carrera de ingeniería y Otto ejercía como profesor en una de las materias de la currícula. Así fue que Otto se constituyó, en los primeros tiempos de relación, en una persona de consulta para Luchessi y luego en un compañero de militancia porque el mismo Pablo lo convenció de conocer a Raúl Alfonsín (en 1979) y éste lo convenció para que militara en el Movimiento de Renovación y Cambio. Luego de ese encuentro se afilió al partido y al año siguiente ya había sido invitado por Raúl Alconada Sempé al Congreso Nacional de Educación de la UCR, donde participó junto a Ángel Plastino, a Gustavo Callejas y a Iglesias, entre otros. ${ }^{26}$

La mirada de Luchessi sobre los meses previos a la formación de la Fundación en La Plata, es que si bien la generación anterior a él no había perdido el tren sino todo lo contrario, había perdido los vínculos con la política. Afirma que "la juventud es más dinámica” entonces iban y venían desde Buenos Aires, los veían a Alfonsín, a Raúl Borrás, a Roque Carranza, etc. Aprendían de sus mayores y cuando regresaban a La Plata, iban a buscar a un grupo de ingenieros, o a médicos, agrónomos, veterinarios, etc., para

ir armando los grupos técnicos, partidarios o no siempre partidarios, porque no era una cosa de buscar radicales. Nosotros partíamos de aquella cosa que dije en principio: teníamos una mirada del bien común más allá de la bandera partidaria. No veníamos del anti-peronista, no veníamos de 'Patria o muerte. Perón o...', no. No veníamos de eso. Pese al esfuerzo de los Montoneros y de la CNU y demás, seguíamos pensando que esto era mucho más abierto y que así eran los países que avanzaban. No sobre la base de odios y muerte y... Bueno, sobre esa base en el '78 conformamos un grupo de profesionales y técnicos para el desarrollo nacional (Luchessi, Entrevista a Quinteros, 3/10/17).

Para Luchessi, el desarrollo era el objetivo de la militancia, planteo que confluirá con el de la Fundación. Mientras tanto, los jóvenes organizaban reuniones con profesionales de diferentes áreas técnicas a las que asistía Raúl Alfonsín. De ese modo se fueron armando líneas de trabajo para eventualmente influir en las políticas de Estado, porque "si se sentaba Juan Estándar Oil, del otro lado se tenía que sentar alguien que supiera de petróleo, para manejar YPF” (Luchessi, Entrevista a Quinteros, 3/10/17) Es decir que ese grupo de jóvenes había incorporado para sí, la idea de sus mayores de que había que capacitarse la intervención política.

El equipo de la fundación se dividió en tres comisiones de trabajo referidas a las temáticas de vivienda, energía y educación. Luego, se intentó generar una cuarta de justicia pero no funcionó. De allí salió un trabajo importante sobre energía que estuvo dirigido por Gustavo Callejas y el "negro" Iglesias, otro sobre 
vivienda diseñado por Jorge Lombardi y un tercero, que fue la base para el proceso de normalización de las universidades nacionales cuyo autor fue Raúl Pessacq. En ese sentido, por cada área de trabajo había, al menos, un referente que presentaba la propuesta para el resto del grupo y discutía los pormenores del planteo. A veces, las diferentes experiencias profesionales y no políticas hacían emerger disidencias que dirimían luego de exponer la propuesta. Pessacq recuerda una discusión bastante densa que se había manifestado en una de las reuniones plenarias sobre educación donde, en el marco de su proyecto educativo universitario, trataron el tema de los cargos concursados de los profesores universitarios durante la época del Proceso de Reorganización Nacional. ${ }^{27}$ Varios de los miembros allí presentes sostuvieron que había que expulsar a todos los docentes de la universidad que habían concursado sus cargos en aquel periodo. Otros habían experimentado situaciones similares en el pasado y eran conscientes de antemano de la diversidad de casos que podían emerger en la universidad. Oscar Giacomantone, decano normalizador por la Facultad de Ciencias Médicas opinó sobre su gestión en una entrevista que "no podíamos poner a todos en la misma bolsa. No podíamos señalar a un tipo que lo obligaron a estar ahí y le sacaron una foto [se refiere a que con el regreso a la democracia, en algunos círculos, se manifestaron actitudes acusatorias, macartistas]. Vos no podés decirle a un tipo: saque patente de valiente" (Quinteros, Pessacq, Banzato, 2019, p. 27).

Pessacq coincidió con Giacomantone sobre el hecho de que la dinámica propia de cada facultad probablemente impactaba sobre el cuerpo docente y sobre sus lógicas de funcionamiento institucional. En ese sentido, no se podía tomar una decisión unívoca y general sino una directiva aplicable a la realidad de cada unidad académica. Lo expresaba con estas palabras:

A mí me cascotearon mucho por el proyecto que presenté de las universidades. No le gustaba a nadie (...) Por ejemplo, todos querían tirar abajo todos los concursos que había hecho el proceso y yo que estaba adentro de la universidad sabía, yo también había concursado y había ganado concurso. No todos fueron iguales, en los lugares donde había política sí, pero no en todos los lugares. En Humanidades que estaba Evans fue un espanto (...) (Pessacq, comunicación personal a Santilli, 2018).

La consideración de Pessacq resulta coincidente con lo que pasó luego durante el proceso de normalización en la Universidad Nacional de La Plata. De los concursos revisados, una buena cantidad fueron dados de baja, los cuales en su gran mayoría, pertenecían a las facultades que más problemas atravesaron por cuestiones ideológicas como lo fueron las de Derecho, Económicas, Periodismo, Bellas Artes y Humanidades. ${ }^{28} \mathrm{El}$ tratamiento y la resolución de las designaciones de los docentes en sus cargos fue un tema central para la gestión académica de las facultades. A su vez, desde el periodo 70-72 no había habido concursos en la universidad y se habían adjudicado del 73 al 76 cargos por interinato "...quedando así a la voluntad de las autoridades universitarias en lo referente a su estabilidad y permanencia en el cargo” (Pessacq, 1987, p. 45). La directiva había sido que ningún concurso dado de baja podía generar problemas legales a la democracia y mucho menos, que pudiera inventarse un juicio donde ganara un "alcahuete" de la dictadura. En esa delicada línea en la que no debía haber margen de error o acciones dudosas que generaran problemas de interpretación se contempló, mediante el artículo 10 de la Ley 23.068, revisar “...la situación del personal docente y no docente declarado cesante, prescindible u obligado a renunciar por motivos políticos, gremiales o conexos" (Pessacq, 1987, p. 116). Para llevar adelante esa norma se sancionó la ordenanza número 162, mediante la cual se reincorporaba todo el personal cesanteado en el periodo de dictadura por actos cometidos en ese momento, o que hubieran sido separados de su cargo sin previo juicio académico.

\section{IDEAS Y SELECCIÓN DE FUNCIONARIOS}

Las universidades nacionales de la Argentina se rigieron por el Decreto 154/83 para entrar en funciones durante el periodo de gobierno democrático y lo hicieron ejecutando el "régimen provisorio de funcionamiento" que daría lugar a la autonomía universitaria. Ese decreto lo elaboró Raúl Pessacq a partir de un pedido expreso de Carlos Alconada Aramburú, y recogía los principios de los ideólogos de la universidad 
reformista que se habían plasmado en el Decreto-ley 6403/55. Los principios se referían, entre otros, a la autonomía universitaria entendiendo a ésta en su independencia financiera y de autarquía moral, el llamado a concurso para cubrir cargos docentes respetando una serie de requisitos profesionales y morales, con su respectivo organigrama que respaldaba y posibilitaba en términos administrativos esos criterios.

El decreto 154 se había pensado también para otros momentos de la historia argentina, e incluso su autor reconocía que las premisas contenidas eran obra de la actividad en conjunto en UDIR y en un largo camino de trabajo militante que estimaba: “...lo que pedimos en el 74, vuelve a estar ahí en el 154, y que viene de lo que son los estatutos nuestros.... Había una gran continuidad ideológica en eso. Del 60 al 83 la continuidad era tremenda" (Pessacq, 2018, comunicación personal).

La identificación de Pessacq con el colectivo reformista y su forma de pensar la universidad había estructurado gran parte de sus decisiones respecto del proceso de normalización dado en la UNLP. Sus comentarios reivindicaban esa historia militante en el movimiento a partir del cual habían dado sus primeros pasos y alertaba sobre la singularidad en el tipo de perfil reformista. Éste combinó la vida universitaria con la profesional e hizo corresponder las especialidades formativas dadas en el plano educativo y hacer experiencia en la actividad profesional, tanto en empresas como en cooperativas, en fundaciones, como así también en espacios políticos estatales. Se trataba de ese lugar del profesional que había empezado a constituirse en un egresado de la facultad y que se terminaba de realizar en la comunidad política, social o económica, donde existía ese estrecho vínculo entre los recursos humanos formados por la universidad pública y las demandas del profesional que se necesitaba en la sociedad. En la universidad que tenían en mente los reformistas, se gestaban las propuestas para el desarrollo técnico y profesional en trabajos que se abordaban por fuera de la institución y se obtenían conocimientos de calidad que distinguía a aquellos recibidos en la universidad pública. Esa militancia estaba convencida que la universidad podía ofrecerle al pueblo un tipo de profesional muy bien formado y cuadros políticos con espíritu crítico, libre de sectarismos y capacitados para la resolución de los problemas más importantes de la Argentina. Pablo Luchessi lo expresó de este modo:

El conocimiento excelso estaba en las universidades, por eso defendíamos la universidad pública: para que tuviera acceso el conjunto del pueblo. Quienes quisieran, quienes tuvieran la voluntad y estuvieran dispuestos a hacer el esfuerzo accedían al conocimiento

superior. Entonces, de ahí iban a salir quienes hicieran los programas de salud, de educación, económicos, el modelo de construcción, el modelo agrario, etc. Porque éramos muchachos del pueblo que eran hijos de arrieros, peluqueros, porteros, maquinistas de YPF, lo que fuere. Entonces, por eso defendíamos la universidad y la queríamos excelsa, porque queríamos que nuestros ingenieros supieran más que los de Harvard, que eran los de la Esso. Lo pensábamos así, en términos rudimentarios, tampoco le dábamos mucha vuelta (Quinteros, Pessacq, Banzato, 2018, p. 263).

La tradición reformista renovaba frecuentemente aquella visión que hacía suponer que la universidad de la excelencia académica era una universidad que ofrecía alguna seguridad en cuanto a las posibilidades laborales de los hijos de una generación que no había gozado de tal beneficio. Como ha dicho Graciano, la actuación de "las clases medias hicieron del control de las universidades un aspecto fundamental de su ascenso social, y para estos sectores, la imposición de los principios reformistas les permitió luchar por la dirección de la política universitaria" (2008, p. 56). Les había ofrecido una vida académica que era un bien social invaluable y que entendieron debía redundar en beneficios sociales y económicos dentro de un mercado laboral que demandaba profesionales diversos.

En su rol de rector de la UNLP que ocupó a partir del 28 de diciembre de 1983, Pessacq debió elegir a los decanos de las unidades académicas de la universidad, aceptar de buen modo las sugerencias del Ministro sobre los posibles nombres a ocupar cargos de gestión, como así también de las de la Federación Universitaria de La Plata, que dio los nombres de los estudiantes que ocuparían el Consejo Superior Normalizador. Hacía 17 años que la Universidad se hallaba intervenida, pero entre las novedades de esa que comenzaba, se incluía la participación estudiantil junto con las representaciones de cada Unidad Académica. 
De ese modo, Pessacq trabajó conjuntamente con Pablo Luchessi -quien ocupó el cargo de Secretario General de la UNLP- en la búsqueda de los profesionales que mejor encajaban en los perfiles imaginados por ambos. En ese caso, la identificación de los postulantes se dio a través de la agenda de contactos de Pessacq, que había confeccionado entre quienes había compartido una experiencia profesional y espacios políticos de la vida militante. El citado recuerda:

Teníamos una red. Uno decía, que se yo, ¿alguien para el Liceo de señoritas? ¿quién conoce a alguien? Entonces le preguntabas a todos los conocidos (...) te tiraban dos o tres, cuatro nombres. Buscábamos las direcciones, llamábamos por teléfono. Íbamos con Pablo Luchessi a los lugares donde ellos estaban, le contábamos, le hacíamos la entrevista y cuando salíamos, decíamos ¿te gusta? Sí ¿Te gusta? No y buscábamos a otro. De persona a persona (Pessacq, 2018, comunicación personal).

Según su relato, esa era la manera de hacer militancia de Hipólito Yrigoyen. Las relaciones se tejían de persona a persona y allí también se juzgaba la fidelidad de las partes en esa relación. No era una elección que se apoyara estrictamente en el mérito académico, aunque ello también pesara. No importaba tan sólo el perfil profesional y de gestión, es decir, el tipo de currículum que habría formado a la persona en el pasado sino también su don de gente, la calidad humana, los valores que se advertían a través de su actitud y su discurso.

La línea política alfonsinista que compartían en ese entonces Alconada Aramburú, Pessacq y Luchessi no fue un parteaguas para la selección de los candidatos a formar parte de los decanatos. Dentro de los colaboradores que ocuparon la función de decanos o cargos dentro del rectorado hubo simpatizantes al radicalismo - no necesariamente alfonsinistas-, los que venían de carreras políticas dentro del peronismo, el socialismo o el anarquismo. De modo que en ese consejo se localizaban afiliados radicales como Aníbal Barreda y Humberto Quiroga Lavie, militantes del Partido Intransigente como Roberto Rollié, personalidades con un perfil socialista como lo era José Panetieri y dentro del grupo de las autoridades del rectorado un fiel anarquista como lo fue Hugo Pacheco. En una carta de lectores del 2001, el Dr. Blas Oscar Barletta Decano normalizador de la Facultad de Odontología elegido por Pessacq, expresaba que se sentía en la obligación moral de reconocer a la gestión de la normalización como la mejor de los últimos 30 años. Una de las razones era que

Otto, con su honestidad, su hombría de bien y su independencia para manejar la Universidad posproceso, se rodeó de profesores y personalidades notables independientemente de su ideología, para formar el Consejo Superior Normalizador. No especuló en la elección de sus colaboradores inmediatos (decanos y funcionarios de las diversas áreas), si pertenecían o no al partido del Gobierno. Eligió con absoluta libertad (El Día, 30/04/2001).

El común denominador principal en la selección de colaboradores fue la experiencia que compartieron en algún momento de sus trayectorias personales. En 1983 esos vínculos que tejieron unos y otros en espacios de formación política y académica fue una oportunidad para que terminaran reunidos bajo la gestión normalizadora de la UNLP. La relación entre Pessacq con David Lagmanovich y Jorge Lombardi se dio en la Fundación Eugenio Blanco de La Plata, mientras que con Pablo Luchessi la cercanía vino por el lado del ámbito académico, luego en la Fundación, en el partido y hasta en la vida privada porque se convirtieron en grandes amigos. También la institución universitaria le había brindado el contacto de Carlos Bustamante en los tiempos en que Pessacq participaba en el Consejo Superior de la universidad en representación de los estudiantes, mientras que Bustamante lo hacía en representación de los graduados. ${ }^{29}$

Con otros el trato se estableció en la Liga de Agrupaciones Amigas como era el caso de Hugo Pacheco y Aldo Rossi. El primero, "un tipo con una rectitud total" con quien había iniciado el contacto en la Unión de derecho y, el segundo, el pelado Rossi, que lo conoció de Auténtica, la agrupación reformista de ciencias económicas, y como parte de la amistad que tenían con Gustavo Callejas y el Beto Fontán, así como en vínculos establecidos en su vida privada, porque pasaron por historias amorosas que los habían cruzado por el lazo familiar que tenían sus novias.

A su vez, los contactos en el partido radical le brindaron algunas conexiones y una relación con Nora Pena, "una trabajadora a todo tiempo" que le sugirió dos figuras destacadas en cuanto a su formación académica 
como fue José Panettieri, que era un reconocido historiador y María Celia Agudo de Córsico que realizó un interesante estudio comparativo sobre los ingresos a las universidades en el mundo y era la persona que en ese momento, en ciudad de La Plata- conocía los pormenores sobre los temas relevantes en la educación universitaria.

En general la elección de los decanos fue una tarea dificultosa porque la dictadura provocó un cambio feroz en la estructura y muchos de quienes con anterioridad habían ocupado puestos profesionales de alto rango no tuvieron intenciones de volver a formar parte de la dirección de la universidad. Además, en aquellas facultades, como por ejemplo en la de veterinaria, nadie quería asumir ese puesto porque se temía el control que aún -luego del cambio de gobierno- sostenía el anterior rector de la UNLP, el militar y veterinario, Guillermo Gallo. En palabras de Pessacq: “Ahí no quería agarrar nadie, le tenían pánico porque además se creían que no íbamos a durar nada, que a los tres meses nos mataban a todos, nos tiraban a la zanja. El único que agarró fue Fortunato Dante Zea que era de Chascomús (una ciudad cercana a la ciudad de La Plata) y amigo de Alfonsín. Católico a pie juntilla y que decía: no... con Ricardito y cómo no voy a ir con Ricardito. Lo conocía de chiquitito" (Pessacq, comunicación personal, 2018).

Por otro lado, la elección del cuerpo directivo de las facultades corrió por cuenta de los decanos y sólo en contadas ocasiones - por requerimiento del mismo decano- el rector de la universidad colocó un nombre para algún puesto en esas instituciones. Además, la nueva estructura definió una autoridad interventora que gestionaba sus decisiones con un Consejo Superior normalizador en la que se involucró al claustro estudiantil. Ese cuerpo directivo debió atravesar por varios debates muy álgidos. Uno de ellos, en los inicios de la gestión, giró en torno a los ingresos. La dirección del rectorado apoyaba la posición de establecer un ingreso nivelatorio, mientras que la agrupación Franja Morada junto a los estudiantes, plantearon el ingreso irrestricto. La cuestión se resolvió al imponerse la visión del ingreso nivelatorio y entonces hubo que planificar de qué manera se llevaría a cabo el mismo.

\section{Palabras finales}

Como se ha visto, en los últimos años de la dictadura militar argentina un grupo de militantes mayormente pertenecientes a la UCR, optaron por crear un espacio de reunión y de reflexión política. Este se definió como Fundación Eugenio Blanco sede La Plata. Se planteaba como no circunscripta ni dependiente de ningún partido político, ni de algún perfil académico particular. Era la virtud de una Fundación, que podía tener afinidades políticas con diversos sectores, pero no alinearse partidariamente. Es así que no participaron, ni suscribieron a los ensayos políticos de la época tal como fue la experiencia de la Multipartidaria, sino que mantuvieron una independencia total. Sus miembros se inclinaron a formar un espacio, tal vez más pequeño, pero de trabajo, en el que predominaron los simpatizantes de Raúl Ricardo Alfonsín. Una simpatía que en algunos era militante pero en otros no, como en el propio Pessacq que no tenía una adscripción definida.

Se puede afirmar que se trató de un lugar de estudio, de debate y de elaboración de políticas de Estado para eventualmente ser llevadas a la práctica. Era la idea todavía muy vigente de formar equipos de trabajo, equipos técnicos que pudieran ser convocados por algún gobierno. Si bien es cierto que se preparaban para estar a disposición, ninguno podía suponer que el propio Alfonsín terminara siendo el candidato de la UCR y además que iba a ser el Presidente de la Nación. Corría el año 1982 y estaban muy lejos de suponer un triunfo como el de diciembre de 1983. Dicha cuestión nos habla de una forma de hacer política aprendida en las décadas de 1940 a 1970 y que hundía sus raíces en tradiciones muy anteriores. Pero lo cierto es que había en este grupo una vocación política, fundamentalmente de trabajo y de servicio a la sociedad, sin que por medio existiera un interés económico. Si bien no se puede ser categórico al respecto, ese desinterés personal y en cambio, el interés por contribuir al bien común que planteaban a través de la elaboración de las mejores políticas para el estado, era fruto de un aprendizaje del militante político de las décadas anteriormente señaladas. 
En ese marco no extraña la elección de la figura de Eugenio Blanco, en tanto que en aquella década del 60 era habitual preparar equipos, como el del propio Blanco, para eventualmente formar parte del funcionariado nacional, provincial o municipal. Este grupo platense parece haberse tomado en serio aquella tradición y se preparaban sin saberlo para gobernar. Raúl "Otto" Pessacq fue uno de entre muchos, con la singularidad que fue elegido para encabezar el proceso de "normalización" de la UNLP, seguramente por su empuje, convencimiento y tenacidad en los planteos reformistas, plasmados en sus estudios en la Fundación Blanco de La Plata, que convencieron en definitiva a quien lo eligió, Carlos Alconada Aramburú. Efectivamente no era casual su elección. Había sido militante estudiantil, Presidente de Centro de Estudiantes, Consejero Superior, Docente de su Facultad, personal de apoyo del CONICET y empleado en la actividad privada. Su ejemplo es prácticamente el de todos quienes militaron junto a él, ya sea compartiendo espacios partidarios, como quienes perteneciendo a otras corrientes políticas, trazaron trayectorias similares.

En este avance puede observarse que la Fundación Blanco sirvió de plataforma para posicionar al grupo con muy buenas chances de ser considerados para dirigir a la UNLP. No obstante debe recordarse que el Decreto 154/83 era de alcance nacional y por tanto, de este núcleo militante y de la pluma y trabajo intelectual de Pessacq, salió la idea sobre el método y la forma en que se concebía la Universidad Pública. Aquellas chances se pusieron de manifiesto inmediatamente después del triunfo de Raúl Alfonsín, activándose en el plano local una red de relaciones que vinculó a personas que compartían un mismo ideario. La elección de Pessacq como Rector Normalizador y, a su vez, la elección de Decanos y colaboradores demuestran no solo la afirmación anterior, sino también el hecho de provenir años más, años menos, de la misma generación formada en la Universidad desde fines de los 50 y 60 del siglo XX.

En esa Universidad se formaron militantes con diferentes enfoques políticos, como así también, distintas prácticas militantes. De la que nos hemos ocupado, se trató de un grupo que se conocía de cuando hacían militancia estudiantil, de cuando compartieron como representantes estudiantiles el Consejo Superior, de cuando impulsaron la creación de agrupaciones que nuclearan a diferentes corrientes, etc. Pero también, cabe destacar que todos suscribían al ideario de la Reforma Universitaria (básicamente a la autonomía y el co gobierno), y al hacerlo, a toda una manera de concebir la república y la democracia dentro de la Universidad. Fuera de ella, compartían además, el rechazo a la dictadura y a la idea de que el rumbo que debía tomar la República Argentina era la Democracia.

\section{ReFERENCiAS}

Acuña, M. L. (1984a). De Frondizi a Alfonsin: la tradición politica del radicalismo/1. Ciudad Autónoma de Buenos Aires, Argentina: Centro Editor de América Latina.

Acuña, M. L. (1984b). De Frondizi a Alfonsin: la tradición política del radicalismo/2. Ciudad Autónoma de Buenos Aires, Argentina: Centro Editor de América Latina.

Águila, G. (2008). Dictadura, represión y sociedad en Rosario, 1976/1983. Un estudio sobre la represión y los comportamientos y actitudes sociales en dictadura. Ciudad Autónoma de Buenos Aires, Argentina: Prometeo.

Altamirano, C. (1987). La Coordinadora: elementos para una interpretación. En J. Nun y J. C. Portantiero, J. C. (Comps.), Ensayos sobre la transición democrática en la Argentina. Ciudad Autónoma de Buenos Aires, Argentina: Punto Sur.

Altamirano, C. (2006). Intelectuales.Notas de investigación. Ciudad Autónoma de Buenos Aires, Argentina: Norma.

Azconegui, C. (2018). La dictadura militar argentina y los usos del programa humanitario de protección a refugiados. En S. Lastra (Comp.), Exilios: un campo de estudios en expansión (pp. 19-39). Ciudad Autónoma de Buenos Aires, Argentina: Consejo Latinoamericano de Ciencias Sociales (CLACSO).

Beltrán, M. (2013). La Franja. De la experiencia universitaria al desafío del poder. Ciudad Autónoma de Buenos Aires, Argentina: Aguilar.

Biagini, H. (1998). Juvenilismo y reformismo. Espacios de critica y producción, (24), 9-20. 
Borrelli, M. y Raíces, E. (2019). La revista peronista Línea y la Multipartidaria (1981-1982): unir al campo nacional para aislar a la dictadura. Quinto sol, 23(1). Recuperado de https://biblat.unam.mx/hevila/Quintosol/2019/vo 123/no1/7.pdf

Bounchanavong, M. (2016). Refugiados del sudeste asiático en la dictadura militar argentina (1979-1984) (Tesis de doctorado). Universidad Argentina de la Empresa. Recuperado de https://repositorio.uade.edu.ar/xmlui/hand le/123456789/5952

Buchbinder, P. (2005). Historia de las universidades argentinas. Ciudad Autónoma de Buenos Aires, Argentina: Sudamericana.

Canelo, P. (2016). La militarización del Estado durante la última dictadura militar argentina. Un estudio de los gabinetes del Poder Ejecutivo Nacional entre 1976 y 1983. Historia Critica, (62), 57-75. https://doi.org/10.7 440/histcrit62.2016.03

Comisión Provincial por la Memoria (18/07/2019). Sitio oficial. Recuperado de http://www.comisionporlamemori a.org/la-cpm/integrantes/luis-julian-lima/

Devés Valdés, E. (2007). Redes intelectuales en América Latina. Hacia la constitución de una comunidad intelectual. Santiago de Chile, Chile: Instituto de Estudios Avanzados-Universidad Santiago de Chile.

Franco, M. (2018a). Nuevas miradas sobre el "Documento final" y las tensiones políticas en torno al "problema de los desaparecidos" en la etapa final de la dictadura argentina. Antiteses, 11(21), 244-266. Recuperado de https://di alnet.unirioja.es/servlet/articulo?codigo $=6571278$

Franco, M. (2018b). El final del silencio. Dictadura, sociedad y derechos humanos en la transición (Argentina, 1979-1983). Ciudad Autónoma de Buenos Aires, Argentina: Fondo de Cultura Económica.

Fundación Eugenio A. Blanco (1986). Argentina: de la transición al despegue. Ciudad Autónoma de Buenos Aires, Argentina: Editorial de la Fundación.

Gallo, E., y Sigal, S. (1963). La formación de los partidos políticos contemporáneos: la Unión Cívica Radical (1890-1916). Desarrollo Económico, 173-230.

Garatte, L. (2008). Grupos académicos y cambios curriculares durante la normalización universitaria en Argentina 1983-1986 (Tesis de maestría). Facultad Latinoamericana de Ciencias Sociales (FLACSO), sede académica Argentina.

Geoghegan, E. (2021). Entre imágenes y palabras: ¿cómo se cuenta la guerra de Malvinas en los textos escolares? Saberes y prácticas escolares en torno a la historia contemporánea y reciente. En M. P. González (Comp.), Saberes y prácticas escolares en torno a la historia contemporánea y reciente: desafios en el abordaje del pasado reciente en la Argentina II, Los Polvorines, Argentina: Universidad Nacional de General Sarmiento. Recuperado de https://ediciones.u ngs.edu.ar/wp-content/uploads/2021/05/9789876305198-completo.pdf\#page $=91$

Graciano, O. (2008). Entre la torre de marfl y el compromiso politico. Intelectuales de izquierda en la Argentina. 1918-1955. Bernal, Argentina: Universidad Nacional de Quilmes.

Lesgart, C. (2003). Usos de la transición a la democracia. Ensayo, ciencia y política en la década del 80. Rosario, Argentina: Homo Sapiens.

Lorenz, F. (2017). La guerra de Malvinas: entre reafirmaciones y vacancias. Pasado Abierto, 3(5). Recuperado de http ://fh.mdp.edu.ar/revistas/index.php/pasadoabierto/article/view/2186

Monsiváis. C. (2007). De los Intelectuales en América Latina. América Latina Hoy Revista de Ciencias Sociales, (47), 15-38. http://revistas.usal.es/index.php/1130-2887/issue/view/152

Muiño, O. (2018). La Guerra de los 100 años. Revolución, martirio y resurrección del movimiento estudiantil. De la Reforma a Franja morada (1918-2018). Ciudad Autónoma de Buenos Aires, Argentina: Lumier.

Morán, S. (2018). La guerra de Malvinas en la transición democrática argentina. Conflictos y tensiones de una agenda política desmalvinizada. Cuadernos de Marte, (15), 173-207. Recuperado de https://publicaciones.sociales.uba. ar/index.php/cuadernosdemarte/article/view/3401

Neiburg, F. y Plotkin, M. (2004). Intelectuales y expertos. Hacia una sociología histórica de la producción del conocimiento sobre la sociedad en la Argentina. En F. Neiburg y M. Plotkin (Comps.), Intelectuales y expertos. La 
constitución del conocimiento social en la Argentina (pp. 15-30). Ciudad Autónoma de Buenos Aires, Argentina: Paidós.

Novaro, M. y Palermo V. (2003). Historia Argentina 9. La dictadura militar 1976/1983. Del golpe de estado a la restauración democrática. Ciudad Autónoma de Buenos Aires, Argentina: Paidós.

O’ Donnell, G. (1997). Contrapuntos: ensayos escogidos sobre autoritarismo y democratización. Ciudad Autónoma de Buenos Aires, Argentina: Paidós.

Pessacq, R. y otros (1987). La normalización de la Universidad Nacional de La Plata 1983-1986. La Plata, Argentina: UNLP.

Ponisio, M. (2016). La capilaridad del gobierno militar durante la última dictadura (1976-1983). Un abordaje de caso desde el nivel de las agencias estatales comunales de la provincia de Santa Fe. Historia regional, (35). Recuperado de http://rephip.unr.edu.ar/handle/2133/16225

Quinteros, G. (2017). A cien años de la Reforma Universitaria. Entrevista a Raúl A. Pessacq, un reformista para construir la Universidad de la democracia. Cuadernos De H Ideas, 11(11), e001. https://doi.org/10.24215/23 $139048 \mathrm{e} 001$

Quinteros, G., Pessacq, R. y Banzato, G. (2018a). Voces de La Reforma en la Universidad Nacional de La Plata. 50 años de dirigencia estudiantil. La Plata, Argentina: Archivo Histórico de la Provincia de Buenos Aires.

Quinteros, G. O., Pessacq, R. A. y Banzato, G. (2019). Las formas de hacer política en la Universidad Nacional de La Plata. Una propuesta reformista en el contexto del tercer peronismo, 1974. Revista Cambios y Permanencias, 10(2), 124-153. Recuperado de https://revistas.uis.edu.co/index.php/revistacyp/article/view/10198/10141

Rock, D. (1977). El radicalismo argentino, 1890-1930. Ciudad Autónoma de Buenos Aires, Argentina: Amorrortu.

Romero, J. L. (1994). Breve historia contemporánea de la Argentina. Ciudad Autónoma de Buenos Aires, Argentina: Fondo de Cultura Económica.

Rubio García, G. (2018). David Peña y la revista Atlántida: expresión de la intelectualidad y la cultura en torno al Centenario de la Revolución de Mayo (1911-1913). Cuadernos de H Ideas, 12(12), e017. https://doi.org/10.2 $4215 / 23139048 \mathrm{e} 017$

Sangrilli, C. (2012). La combativa CGT en tiempos de la guerra de Malvinas (1982). Revista Escuela de Historia, 11(1), $1-23$.

Sigal, S. (2002). Intelectuales y poder en Argentina. La década del sesenta. Ciudad Autónoma de Buenos Aires, Argentina: Siglo XXI.

Taroncher Padilla, M. Á. (2004). Periodistas y prensa semanal en el golpe de estado del 28 de junio de 1966: la caída de Illia y la revolución argentina (Tesis de doctorado). Universitat de Valencia. Recuperado de https://www.td x.cat/bitstream/handle/10803/9957/taroncher.pdf;sequence $=1$

Velázquez Ramírez, A. (2015). De la concertación a la Multipartidaria: el espacio político partidario en los albores de la transición a la democracia en Argentina (1980-1981). Núcleo de Estudos Contemporâneos; Contemporánea, 1(7), 1-28. Recuperado de https://ri.conicet.gov.ar/bitstream/handle/11336/56457/CONICET_Digital_Nro.d31 b5b66-ece0-4128-9738-2eebf7b7eeeb_A.pdf?sequence=2\&isAllowed=y:

Veronelli, C. y Veronelli Correch, M. (2004). Los origenes institucionales de la Salud Pública en la Argentina, (2). Recuperado de https://iris.paho.org/bitstream/handle/10665.2/3477/argentina-salud-publica-historia-tomo2 .pdf? sequence $=1$ \&isAllowed $=\mathrm{y}$

Vestfrid, P. (s/f). La formación en comunicación social en la Escuela Superior de Periodismo y Comunicación Social de la Universidad Nacional de La Plata a partir de la normalización universitaria (1983-1988). Recuperado de h ttp://secyt.presi.unlp.edu.ar/cyt_htm/ebec07/pdf/vestfrid.pdf

\section{Notas}

1 Para ver algunas notas alusivas a este momento transicional y las opiniones expresadas en el periódico del diario $E l$ Día puede consultarse -entre otras- las siguientes notas editoriales: "Libertad vigilada para los partidos políticos" (por 
Armando Emilio Grau del 22/09/82); “Los mercenarios de la pluma” (de Hugo Gambini publicada el 12/09/82) y "Sí, esta vez habrá elecciones” (de Ramiro De Casasbellas del 12/09/82).

2 Le llamaban Liga de Agrupaciones Amigas al conjunto de agrupaciones estudiantiles que perteneciendo a distintas Facultades de la UNLP compartían un ideario común. Por ejemplo: Agrupación de Estudiantes Reformistas (ADER) de medicina, Agrupación Liberal Universitaria (ALU) de ingeniería, Auténtica de económicas, Unión de derecho (Quinteros, Pessacq, Banzato, 2018a: 421 p.).

3 En la Universidad Nacional de La Plata el reformismo fue una corriente de gran influencia política. La misma recogió los principios fundamentales del movimiento de la Reforma Universitaria de 1918 y a partir del cual, se fomentó la institucionalización de la autonomía universitaria, la docencia libre, el cogobierno, las políticas de extensión universitaria y de acceso libre, entre otras. Al respecto, cabe aclarar que esto ha sido una base fundamental para el funcionamiento de las universidades públicas argentinas (Graciano, 2008; Biagini, 1998).

4 Sergio Karacachoff (27/06/1939-10/09/1976) fue un militante reformista de la Facultad de Derecho, periodista, abogado laboralista y dirigente de la Unión Cívica Radical, secuestrado en la puerta de casa de su socio Domingo Teruggi por fuerzas policiales. Su cuerpo fue hallado dos días después junto a Teruggi, camino a la ciudad de Magdalena. Las referencias son de Jorge Lombardi (comunicación personal, 12/2015). Cfr. Muiño, 2018, pp. 582-583

5 El arquitecto Jorge Lombardi fue Decano normalizador de la Facultad de Arquitectura y Urbanismo durante el periodo 1983-1986, y en el tramo siguiente fue nombrado por elección del Consejo Académico ampliado. Fue militante activo de la Unión Cívica Radical.

6 Una de las primeras en crearse y de las más representativas fue la Asamblea Permanente por los Derechos Humanos (APDH), en diciembre de 1975. Nació a raíz de los asesinatos cometidos por un grupo paramilitar denominado la triple A (Alianza Anticomunista Argentina). Según plantean Novaro y Palermo (2003) para los 80, "La intransigencia que mostraron la OEA y los Estados Unidos en esta negociación (se refiere a la misión de CIDH en la Argentina) se originó, al menos en parte, en el hecho de que la Argentina ya no era, a esa altura un caso más entre los 'violadores sistemáticos' de los derechos humanos: la aberración de las desapariciones y el impresionante volumen de información reunida por la embajada norteamericana y los organismos de derechos humanos habían tenido un impacto conmovedor en los Estados Unidos, Europa e incluso en países latinoamericanos para los cuales la violencia política y las dictaduras no eran ajenos"(p. 295).

7 ACNUR: Alto Comisionado de las Naciones Unidas para los Refugiados. El pedido de refugio fue lanzado en Ginebra en 1979

8 El 10 de diciembre de 1983 la Multipartidaria se disolvió. En la Argentina del siglo XX ha habido dos partidos políticos que captaron a las grandes mayorías populares, a saber la Unión Cívica Radical nacida de una revolución armada contra el gobierno de turno en 1890; y el Partido Peronista surgido de las jornadas del 17 y 18 de octubre de 1945, cuando una multitud pidió por la liberación del Coronel Juan Domingo Perón (Gallo \&. Sigal, 1963; Rock, 1977; Asimismo, el Movimiento de Integración y Desarrollo fue un partido creado en la década del 60 con una orientación desarrollista que siguió los principios del frondizismo (Acuña, 1984a, 1984b; Romero, 1994).

9 Se produce lo que Guillermo O’ Donnell (1997) denominó “repolitización” de la sociedad civil donde se multiplican posturas y actitudes, individuales y colectivas en contra del régimen militar.

10 La discusión al respecto del par Autoritarismo/Democracia fue actualizada en el trascurso de los años y esto hizo que emergieran algunos de los debates que habían sido postergados. A modo de ejemplo puede indicarse que: si en los 80, los desaparecidos habían sido considerados víctimas inocentes del terrorismo de estado, en los 90, la organización Madres de Plaza de Mayo contribuirán a reconstruir su identidad militante. Lesgart ha desarrollado un análisis sobre los puntos críticos que observaron diferentes interlocutores a la democracia y en tal sentido ha dicho que “... pareciera que la crítica está colocada en cómo los años 80 necesitaron despolitizar -deshistorizar es la palabra corrientemente utilizada- el pasado militante. (...).(Lesgart, 2003, p. 191)

11 Esa lectura de la historia fue plasmada en la película documental "La República perdida”, ampliamente difundida a partir de su estreno, el 1 de septiembre de 1983 (Dirección de Miguel Pérez y Guion de Luis Gregorich)

12 Eugenio Blanco fue militante de la Unión Cívica Radical y cumplió funciones como ministro de economía durante la gestión de Pedro Eugenio Aramburu y de Arturo Illia. Ver: http://cdi.mecon.gov.ar/biblioteca/listado-de-ministros-d e-economia/ Consultado: 04/10/18. Más abajo se dan detalles sobre dicha personalidad.

13 El Lic. Callejas fue Subsecretario de Combustibles entre 1983-1989

14 Las referencias fueron del Ingeniero Pablo Luchessi a quien agradecemos su colaboración. Comunicación personal a Quinteros, 3/10/2017

15 Pessacq fue rector normalizador en el Proceso de Normalización de la Universidad Nacional de La Plata que se dio entre los años 1983-1986. En ese periodo se buscó poner en funcionamiento el sistema democrático universitario con una normativa que lo hiciera posible. 
16 Ricardo Balbín fue el líder de la Intransigencia de Buenos Aires, una tendencia dentro del partido radical, que mantuvo una posición de poder desde el momento en que el partido se dividió en 1957 y controló ese espacio hasta su muerte en 1981.

17 Una semblanza de Blanco se encuentra en Fundación Eugenio A. Blanco, 1986

18 En 1985 se inauguró la Cátedra del Pensamiento Democrático y en las palabras alusivas, se decía que con ella culminaba “...el décimo séptimo años académico de la institución” Fundación Eugenio A Blanco, 1986, p. 15

19 Parte de la actuación Caeiro, Alconada Aramburú, Concepción, Grinspun, etc., durante el Gobierno de Illia en la tesis doctoral de Taroncher Padilla, 2004.

20 Juan Sábato fue ingeniero y se destacó por su trabajo en materia de energía tecnológica. Fue militante socialista e integrante del grupo de especialistas que le dio forma al proyecto del que YPF realizaría el gasoducto en la ciudad de Buenos Aires. Carlos Alconada Aramburú fue abogado y docente universitario. Ministro de Educación y Justicia en el Gobierno de Arturo Illia y en el de Raúl Alfonsín. Andés Ringuelet fue "Ingeniero Agrónomo de la Universidad Nacional de La Plata" (Quinteros, 2017, p. 12). Todos fueron militantes del movimiento reformista.

21 Para ver información sobre UDIR, ver Quinteros, G., Pessacq, R. y Banzato, G., 2019.

22 Consideraciones de este estilo pueden encontrarse en el grupo de entrevistas realizadas a miembros de agrupaciones reformistas que militaron en distintas unidades académicas de la Universidad Nacional de La Plata (Quinteros, G., Pessacq, R. y Banzato, G., 2018a). A su vez, la caracterización encaja perfectamente con la realizada por Silvia Sigal al respecto de facetas que ha establecido la universidad en distintos periodos de la historia donde la universidad se define como reformista, y no como peronista, del proceso o si se quiere radical: “...cuando el control del Estado cambia de manos, los intelectuales pertenecientes al bloque reformista son desplazados por miembros de algunas de las corrientes anti-reforma, en nombre de valores que ligan también cultura y política. Más que 'La Universidad' habrá entonces 'la universidad peronista' de 1946 a 1955, 'la universidad reformista' de 1955 a 1966, 'la universidad peronista, segunda versión' después de 1973, 'la universidad del Proceso' entre 1976 y 1983 y, luego, 'la universidad democrática'” (Sigal, 2002, p. 55).

23 El Ing. Martínez Civelli, un hombre ya mayor, dijo en el 83 cuando el diario el El Día le consultó cuál era la Universidad que deseaba: "No hay república sin republicanos, y no hay universidad republicana sin universitarios republicanos. Quiero una universidad que no vuelva a ser una trinchera de subversión facciosa ni un cuartel para la obediencia ciega, en la que no nos encontremos ni con instructores de asesinos, ni con instructores de asesinos, de los asesinos. Quiero una Universidad que incluya entre sus deberes la tentativa de formar sus propios miembros republicanos, que construya a la salvación de la libertad, después de decenios de devastación, que no se comprometa con ningún partido sino con el entero" (El Dia, 5/06/1983, p. 5).

24 El Ingeniero Luis Julián Lima fue, docente, decano normalizador por la Facultad de Ingeniería en 1983-1986 y rector de la Universidad Nacional de La Plata durante el periodo 1992-2001. (Comisión Provincial por la memoria, 18/07/2019).

25 La Junta Coordinadora Nacional había nacido con ese nombre en, Setúbal -provincia de Santa Fe- en 1968. Se constituyó mayoritariamente por militantes universitarios que habían incorporado -como ha señalado Altamiranoprácticas de militancia nuevas - respecto del estilo de militancia radical- de sus rivales de izquierda universitaria. De alguna manera, este grupo vino a ocupar el lugar del movimiento reformista que se había erosionado en 1966. A su vez, constituyó una alternativa universitaria debido a que ni la izquierda revolucionaria, ni el peronismo de izquierda veían como una opción posible la salida electoral y apuntaban, más bien, a una postura que la ignoraba o rechazaba. Alguno de sus miembros terminaron ocupando cargos en el gobierno de Alfonsín y existieron algunas circunstancias que no pueden ser soslayadas a la hora de pensar en el triunfo de la fórmula. Esto según ha señalado Altamirano estuvo relacionado entre otras cosas, a la muerte de Balbín en 1982, la postura adoptada por el balbinismo frente a la Guerra de Malvinas, y "la erosión que había sufrido la imagen colectiva del peronismo" (1987, p. 316).

26 Según señala Garatte en su trabajo de tesis, Alconada Sempé era hijo de Carlos Alconada Aramburú y un cuadro político platense de importancia que había pertenecido a la "Coordinadora", cuando ésta entabló relaciones con el Movimiento de Renovación y Cambio. En 1983, momento en que su padre cumplió funciones en el cargo de ministro de educación y justicia fue su mano derecha.

27 De esa manera, la junta militar constituida por las tres armas denominó al proceso que abría en 1976 "cuyos objetivos serían reestablecer el orden, reorganizar las instituciones y crear las condiciones para una 'auténtica democracia”" (Novaro y Palermo, 2003, pp. 19-20). Con esa retórica implementó un régimen terrorista y totalitario.

28 El decreto 154, en su artículo 7, suspendía la sustanciación de todos los concursos universitarios, razón por la cual quienes dirigieran el proceso de normalización de la UNLP debieron "reevaluar" su validez. Según ha señalado Pessacq: los concursos fueron valorados uno por uno por parte de un grupo designado para este fin.

29 Sobre Carlos Bustamante algunas referencias en Vestfrid, P., s/f. Pessacq agrega que había convocado a varios profesionales que habían formado parte de ese consejo superior pero no obtuvo éxito y como ha afirmado: "Nadie quería volver, era un quilombo". Su expresión es coincidente con otros testimonios referidos a que existía un común 
CUADERNOS DE H IDEAS, 2021, 15(15), E044, ISSN: 2313-9048

convencimiento detrás de la euforia democrática de que el gobierno no iba a durar, de que volverían los militares y, en el extremo, que las cosas se iban a poner peor respecto de la represión de estado. 